\title{
The Potential of Mobile Phones to Transform Teacher Professional Development to Build Sustainable Educational Futures in Bangladesh
}

\author{
Christopher S. Walsh* \\ Torrens University Australia, Australia
}

Clare Woodward, Mike Solly and Prithvi Shrestha

Faculty of Education Studies, The Open University, UK

\begin{abstract}
Futures thinking is used by governments to consider long-term strategic approaches and develop policies and practices that are potentially resilient to future uncertainty. English in Action (EIA), arguably the world's largest English language teacher professional development (TPD) project, used futures thinking to author possible, probable and preferable future scenarios to solve the project's greatest technological challenge: how to deliver audio-visual TPD materials and hundreds of classroom audio resources to 75,000 teachers by 2017. Authoring future scenarios and engaging in possibility thinking (PT) provided us with a taxonomy of question-posing and question-responding that assisted the project team in being creative. This process informed the successful pilot testing of a mobile-phone-based technology kit to deliver TPD resources within an open distance learning (ODL) platform. Taking the risk and having the foresight to trial mobile phones in remote rural areas with teachers and students led to unforeseen innovation. As a result, EIA is currently using a mobile-phone-based technology kit with 12,500 teachers to improve the English language proficiency of 700,000 students. As the project scales up in its third and final phase, we are using the new technology kit — known as the 'trainer in your pocket' to foster a 'quiet revolution' in the provision of professional development for teachers at scale to an additional 67,500 teachers and nearly 10 million students.
\end{abstract}

Keywords: futures thinking, school-based professional development (SBPD) model, teacher professional development (TPD), mobile phones, open distance learning (ODL)

\section{Introduction}

The past decade has seen dramatic shifts in the context for international development in emerging economies such as Bangladesh, particularly in the provision of English language teaching with the intended aim of providing citizens with increased economic and social opportunities. Increasingly faced with limited financial resources, many initially successful international development programmes stop abruptly when funding runs out, unless there is sustainability and institutionalization planning explicitly built into the program's design. Effective sustainability planning requires individuals and organizations to think strategically about the future.

\footnotetext{
* Corresponding author. Email: Christopher.walsh@tua.edu.au
} 
Futures studies has been formalized in educational, industrial and government fields to forecast potential alternative futures to a 'probable' future to ensure a higher probability of 'success'. Futures thinking's scenario method of postulating different possible futures encourages collaboration to consider plausible alternatives to the status quo, or what is likely 'probable' in the future. The approach is fluid and sees the future as a problem to be solved, explicitly linked to actions in the present. Through the authoring and critique of probable, possible and preferable future scenarios, English in Action (EIA) was empowered to explore and pilot mobile phone technologies to build an alternative vision of the future that we could work for in the present. EIA's vision of the future was unequivocally premised on the implementation of a sustainable and robust large-scale school-based professional development (SBPD) model capable of improving the English language competence of nearly 10 million Bangladeshi school children and 75,000 English teachers from 2009 to 2017.

\section{Mobile phones to teach English?}

There are few examples of international development projects using mobile phones to deliver TPD. The studies that do exist are small in scale and generally provide examples of students using their own mobile phones to learn English (Cavus \& Ibrahim, 2009; Salameh, 2011; Thorton \& Houser, 2005), or explore their attitudes towards using phones to learn English (Dang, 2013). Current research on using mobile phones for TPD tends to focus on the development of awareness of the potential of mobile devices for learning (Schuck et al., 2013), using tablets in challenging educational contexts (Onguko, 2014) or changing teacher attitudes towards the use of mobile phones in teaching (Ekanayake \& Wishart, 2014).

Presently, EIA is successfully providing an innovative SBPD model that leverages the power of mobile phones to make audio-visual TPD materials and classroom resources available to 12,500 teachers and nearly 700,000 students through an ODL platform (Power et al., 2012; Shrestha, 2013; Walsh et al., 2013). Over the next three years, the project will deliver this TPD through the SBPD model to an additional 67,500 teachers and nearly 10 million students.

\section{English in Action (EIA)}

The importance of using information and communication technologies (ICTs) to learn English and to improve the social and economic prospects of all Bangladeshis, particularly those living in poverty, is a Bangladesh government priority. As a result, English in Action (EIA) - a nine-year English language teaching education programme striving to improve the communicative English language skills of 25 million Bangladeshis - was launched in 2008. This collaborative project ${ }^{1}$ is funded by UKaid

\footnotetext{
1 For more information on EIA's partners see http://www.eiabd.com/eia/index.php/abouts/project-partners
} 
from the Department for International Development (DfID) and works closely with the Government of Bangladesh's Ministry of Primary and Mass Education (MoPME) and the Ministry of Education (MoE). The project is dedicated to changing English language learning by making it more student-centred, thereby potentially changing lives in the future because students will be able to communicate in English at levels which enable them to participate more fully in economic and social opportunities.

EIA hopes to contribute significantly to the economic growth of Bangladesh by providing communicative English language as a tool for better access to the world economy. The project consists of a consortium of partners working together: BMB Mott MacDonald; BBC Media Action (previously BBC World Service Trust); The Open University, UK; and two Bangladeshi non-governmental organizations (NGOs): the Underprivileged Children's Educational Programme (UCEP) and Friends in Village Development Bangladesh (FIVDB). The project partners bring unique specialized expertise to achieve the project's goals. BBC Media Action provides a diversity of programmes aimed at improving 13 million adult learners' communicative English language skills ${ }^{2}$.

Importantly, EIA's work is closely aligned with the democratic government of Bangladesh's Prime Minister's Office's philosophy of 'Digital Bangladesh' (Monodol $\&$ Walsh, 2011). The philosophy of 'Digital Bangladesh' is an attempt to ensure democracy and rights to the citizens of Bangladesh. It aims to be transparent, accountable, establish justice and ensure the delivery of government services through the widespread use of technology to improve the lives of Bangladeshis, regardless of class or social status. EIA's innovative SBPD model and TPD programme are situated within existing government initiatives to provide teacher professional development at scale to 75,000 teachers by 2017 , using mobile phones through open distance learning (ODL) with audio and video resources on 4GB micro secure digital (SD) cards. The programme also supplies teachers with supplementary print teacher guides and visual resources for both primary and secondary English teachers.

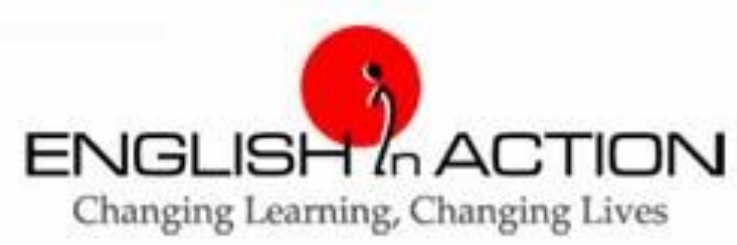

Figure 5 English in Action's (EIA) logo and slogan

EIA's School-based Professional Development (SBPD) model

\footnotetext{
${ }^{2}$ For more information see http://www.bbc.co.uk/mediaaction/search?term=English+in+Action
} 
EIA's School-based Professional Development (SBPD) model is an innovative form of TPD that assists teachers in learning and applying new English language teaching practices in the classrooms, schools and communities where they work. Through school-based ODL - supported by a diversity of mediated authentic videos (MAVs) (Woodward, Griffiths \& Solly, 2014) and audio classroom resources accessible on teachers' mobile phones, or the 'trainer in your pocket' (Walsh et al., 2013) - the classroom becomes the nexus of learning (Walsh \& Power, 2011). EIA's SBPD model stands out because it is an efficacious mobile learning solution for the field of international development that does not leave teachers on their own to make sense of ODL materials and TPD resources. Teachers learn how to access and use EIA's resources while receiving support from a teacher-partner within their school, a community of teacher colleagues from their upazilas (sub-districts) and through bi-monthly project cluster meetings across 16 months. This bespoke programme assists teachers in developing, supporting and sustaining new communicative and student-centred pedagogic practices while simultaneously improving their own English language proficiency.

Participation in new classroom activities is at the heart of teachers' TPD with the EIA's SBPD model. Teachers are able to view, review and try out new teaching practices exemplified by peer teachers who have themselves been participants in the project. There are two additional layers of support helping teachers in carrying out these new activities: 'support in school'; and 'beyond the school. 'Support in school' includes an extensive collection of audio resources for primary students, directly aligned with Bangladesh's national English textbook English for Today books 1-5 (NCTB, 2013). In total, there are currently 452 audio lessons for the primary classroom and 190 audio resources for the secondary classroom, which include audio recordings of many stories, dialogues, passages and poems from English for Today books 6-10. Additional support in school is provided by the head teachers and through peer support as two teachers from each selected school attend the 16-month cycle of EIA's SBPD. 'Support beyond the school' includes peer support, cluster meetings and wider project support, including school visits, knowledge-sharing and a FaceBook page ${ }^{3}$.

\footnotetext{
${ }^{3}$ https://www.facebook.com/EnglishInActionBangladesh
} 


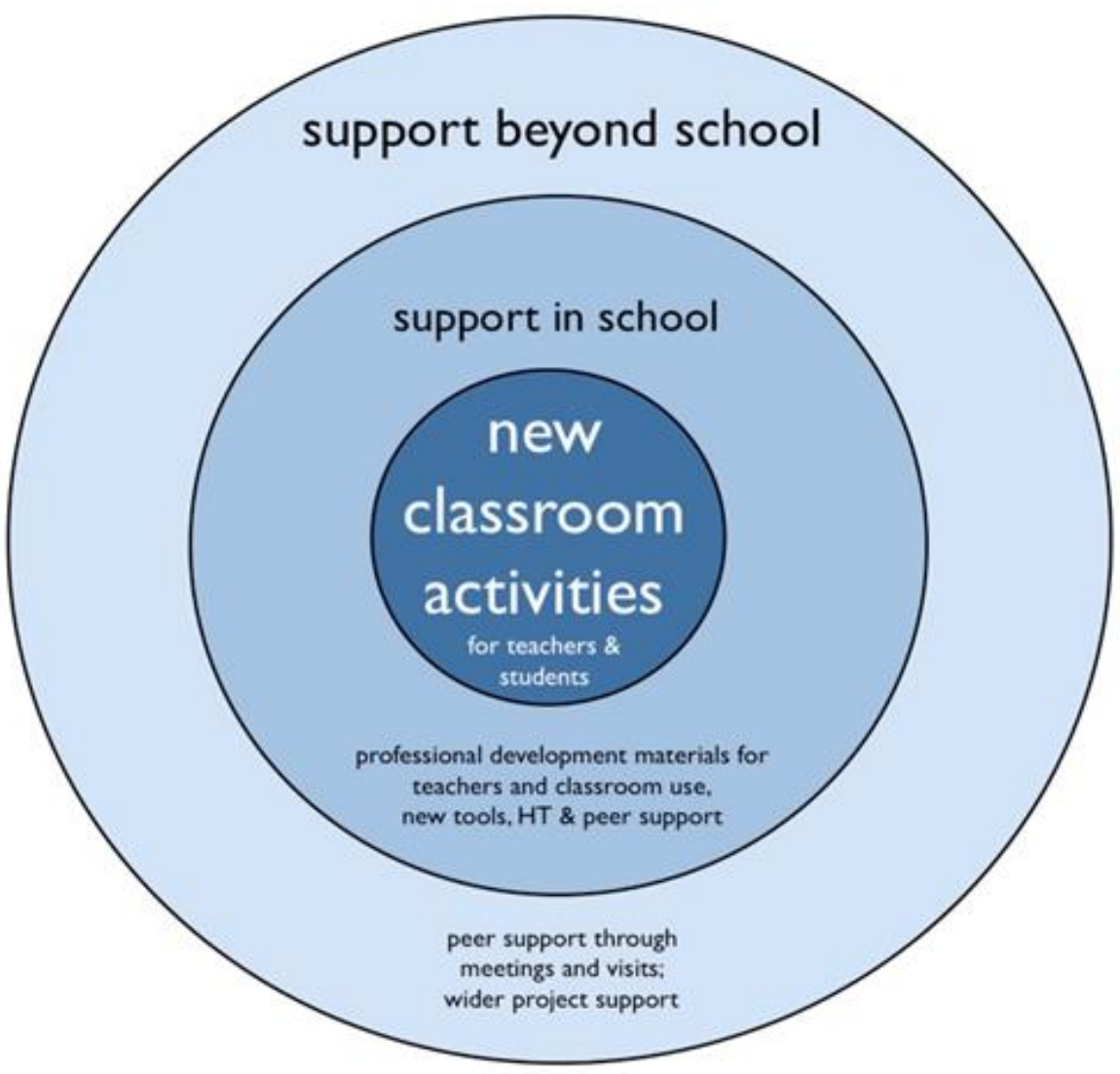

Figure 6 EIA’s SBPD model (Walsh \& Power, 2011)

\section{EIA's developmental research}

EIA's developmental research was carried out with 700 teachers from government schools across 21 of Bangladesh's upazilas (2008-2011). Two-thirds of these teachers worked in primary schools and one-third in secondary schools. Approximately $80 \%$ of all EIA schools were in rural areas with limited or no access to electricity. The developmental research helped the project to explore the use of mobile technologies or eLearning for English teachers' TPD and the delivery of audio resources for classroom use (Walsh, 2011).

EIA's development research (2009-2010) provided extensive audio and visual resources to primary and secondary English teachers through a technology kit with either the Apple iPod Nano (for primary teachers) or iPod Touch (for secondary teachers), both with portable rechargeable speakers. The iPods were chosen because the project team believed the teachers would find the use of the Apple MP3 players relatively easy. Although iPods were more expensive than other devices available at the time, they were selected because they had the functionalities the project team believed necessary to provide teacher TPD through an ODL platform supported by EIA's SBPD 
model. These crucial resources, played on portable rechargeable speakers, were also chosen because they were thought to have the best possible chance of improving the communicative English proficiencies of both students and teachers.

\section{External research, monitoring and evaluation (RME)}

To assess the EIA's developmental research and initial pilot studies, Trinity College was engaged to externally evaluate the project, using the Trinity Graded Examinations in Spoken English (Trinity College London, 2007). Students and teachers were interviewed in English and this was evaluated against the criteria of the 12-point Trinity College English Language scale. Grade 1 on the scale represents limited, or little, spoken English competence and grade 12 indicates complete competence. The Trinity grades are sub-divided into four stages: initial (1-3); elementary (4-6); intermediate (79); and advanced (10-12). In 2010, Trinity assessors used questionnaires to assess 4,630 primary and 2,609 secondary students' English language competence before their teachers participated in EIA's CPD programme. Then in 2011, Trinity assessed 786 primary and 318 secondary students from the 2010 cohort. For primary students, prior to the teachers' participation in EIA, $64.3 \%$ of students failed to pass the Trinity's graded examination. In 2011, that number dropped to 49.9\%. In 2010, 35.4\% of the students scored initial levels (passing) of English language competency, and this number rose to $50.1 \%$ in 2011. In secondary school, while the proportion of students who failed (below grade 1) dropped from $28.9 \%$ to $10.4 \%$ in 2011, the number of students who passed at the initial levels (grades 1-3) rose from $61.9 \%$ to $66.6 \%$. Students passing at the elementary level (grade 4-6) rose from 9.2\% to $22.4 \%$, a considerable increase. Both internal and external evaluation of the project's Phase 1 intervention indicates EIA's teacher CPD, and the use of the iPods, were successful at encouraging higher percentages of teachers and students to speak English in the classroom. Additionally, the Trinity research indicates that teachers and students acquired higher levels of communicative (speaking and listening) English language competency after participating in the project.

\section{Challenges}

Although the pilot phase was successful in terms of the iPods used for teachers' TPD, there were considerable challenges reported. Teachers experienced difficulty in trying out and incorporating the new student-centred pedagogy demonstrated in the TPD resources, even though these were also introduced in cluster meetings. A significant technological challenge was that many teachers found it extremely difficult to charge both the iPod and portable speaker - in addition to their own mobile phones - due to the intermittent availability of electricity across Bangladesh.

After the results of Trinity College's external evaluation of EIA's pilot study, the project was able to identify teachers participating in EIA who were successfully using the projects' audio, authentic mediated videos and print resources to transform their 
English language teaching. They were no longer using the grammar translation method; rather they had fully integrated CLT practices and their students were speaking and communicating in English. Recruiting a selected group of these teachers from locations around the country, a film crew, together with several UK Open University academics, travelled to mainly rural locations across Bangladesh and filmed the teachers using the CLT techniques acquired and EIA educational resources. They were filmed with their own students, in their own classrooms, using EIA's educational resources explicitly aligned with English for Today. The lessons were selected based on good practices of communicative language teaching.

\section{Thinking differently about the future}

Mindful of the success of the developmental research, EIA knew that its SBPD model that leveraged the power and flexibility of MP3 players within an ODL platform to deliver TPD was viable and responded to the realities of Bangladesh. But the most significant technological challenge the project encountered was the high cost of the iPod Nano and Touch. These MP3 players are too expensive to provide to 12,500 teachers in the current upscaling phase (2012-2015) and to an additional 67,500 teachers by 2017. More importantly, the research confirmed the viability of such an approach at scale with tens of thousands of teachers.

The project's initial success was a catalyst that pushed us to creatively think and act 'outside the box' to collaboratively overcome our technological and pedagogical challenges. Futures thinking's (Bell, 1997; Sardar, 1999; Slaughter, 2005) scenario method - alongside foresight exercises (Cascio, 2009) and possibility thinking (Craft, 2001) - guided EIA researchers in Dhaka in authoring scenarios for 'possible' and 'preferable' futures over a 'probable' future. This assisted us in solving EIA's technological challenge within the project's budget constraints (Monodol \& Walsh, 2011).

Using futures thinking, alongside possibility thinking, encouraged us to ask 'what if' and 'as if' questions, 'refusing to be stumped by circumstances but being imaginative in order to find a way around a problem' (Craft, 2000, p. 3). By engaging in possibility thinking, we drew on our 'little "c" creativity' or what Craft (2001) refers to as our ability to cope with change in the 21 st century. Our possibility thinking was powerful and helped us to think differently about the future - and to foster our creativity - to find a way to overcome our technological challenge within the project's budget. We individually asked 'what if' questions that were open to different possibilities that we could develop further:

- What if we can't find MP3 players that have screens to view the TPD resources at cost?

- What can we do with the mobile phones teachers already have? 
- What if teachers can access the internet on their own mobile phones in 2014? Or 2017 ?

and

- What if smart phones with enough storage to hold EIA's resources were common across Bangladesh by 2017 ?

Then we came together to engage in the process of collaboratively sharing our questions and problem-posing and problem-finding to engage in divergent and convergent thinking. To answer our 'what if' questions, we scanned the world for multiple perspectives, past and present, from researchers, teachers, electronic vendors and individuals. These diverse perspectives, essentially factors or drivers of what might happen or come to be in Bangladesh, helped us explore how our 'what if' questions could be answered to address the challenges we were confronted with.

\section{Authoring future scenarios}

The collaborative authoring of scenarios - resulting from our possibility thinking - encouraged knowledge-exchange and the development of a deeper understanding of the central issues and factors inherent in the technological challenge EIA faced. We authored three future scenarios to help guide the development of a new technology kit pilot study to choose the best possible kit to deliver EIA's TPD resources to 12,500 teachers through 2015. Below we present our probable and preferable future scenarios. We thought deeply about what actions we would need to take in the present, to bring about our preferable future and avoid the probable future. This stance allowed us to reinforce what EIA was already doing well and build on the project's success in delivering TPD. The scenarios we authored were as follows.

\section{The probable future}

In Bangladesh, particularly from a government perspective outlined in the Digital Bangladesh Concept Note (A2I, Prime Minister's Office, 2009) there is an assumption that ICT will benefit everyone, especially teachers and students. People have greater access to mobile phones and other ICT devices. Access to ICT is more ubiquitous, but not everyone has access. Those living in rural areas still struggle to access the Internet and there is not always a nearby reliable source of energy. While more individuals have access to ICT, they are still struggling with ICT literacy, meaning they don't necessarily have the ICT skills to access and use productively all that is on offer. There is still a 'digital divide' in the ways in which society chooses to make technology accessible and usable to the members of society. There are many hopes pinned on this relationship being constructively arranged, but it has not been entirely realized. There are easily accessible open learn modules that can be accessed on mobile phones to help teachers both improve their English language skills and learn to teach in more communicative ways, but the uptake is not as quick as 
expected, even though many individuals believe learning English will improve their social and economic opportunities.

\section{The preferable future}

Bangladeshi schools, through networked teachers, online teacher training programmes and affordable/accessible network ubiquity have gained a reputation for being able to deliver English language learning tailored to individual needs. The development of learning networks advanced, no longer subject to time and place constraints. Individualized networks emerged as communities collaboratively redefined the work of schools to better serve local needs. Networks of teachers, learners, parents and professionals responded to a changing society to meet the needs of the expanding internationalized knowledge economy. Pupils leave primary school with high levels of English language proficiency while many secondary pupils emerge bilingual. Mobile phone ownership in urban and rural areas has reached saturation. Many individuals own mobile phones, with powerful processors, abundant memory, and larger screens, and open operating systems are used for learning and accessing greater social and economic opportunities.

The 'preferable future' is the one we relied on to answer the project's goal and this led to a pilot test of low-cost mobile phones. This allowed us to reinforce what EIA was already doing well and build on our successes from there [face-to-face and ICT-enhanced teacher professional development, new technology kits, and the new/additional possibilities they offer (i.e. SMS, radio, teacher phone-based networks or 'buddy' systems, an Internet-based open learning course on mobiles, tablets, etc.)]

\section{Low-cost mobile phone pilot study}

EIA was conceptualized to intentionally address issues of scale, embedding and quality for the present and future across rural and urban contexts. Budget constraints of 6,000 Bangladeshi taka per teacher (£60) mandated that EIA construct multiple kits to field-test and pilot for the current upscaling phase (2012-2015), while also thinking post-2015 when there will be much less funding available for the approximately 67,500 teachers to whom EIA will still be required to provide a robust programme of TPD. Drawing on our preferable future scenario and the result of our possibility thinking, we chose two low-cost alphanumeric mobile phones with 4GB micro SD cards and portable rechargeable speakers to pilot as three separate kits from March to September (2011) in two rural upazilas. The results of the mobile-phone-based technology kit were extremely successful, with pilot study teachers overwhelmingly reporting satisfaction and success using the kits with their students. This resulted in EIA assembling a new technology kit that was distributed to 12,500 teachers (January-June 2014) across Bangladesh. The kit (Figure 3) consists of the Nokia C1-01 (£35) mobile phone, a portable rechargeable Lane amplifier/speaker (£25) and all of EIA’s TPD materials and 
classroom audio resources on 4 GB micro SD cards (£2). The kit has affectionately become known as the 'trainer in your pocket'

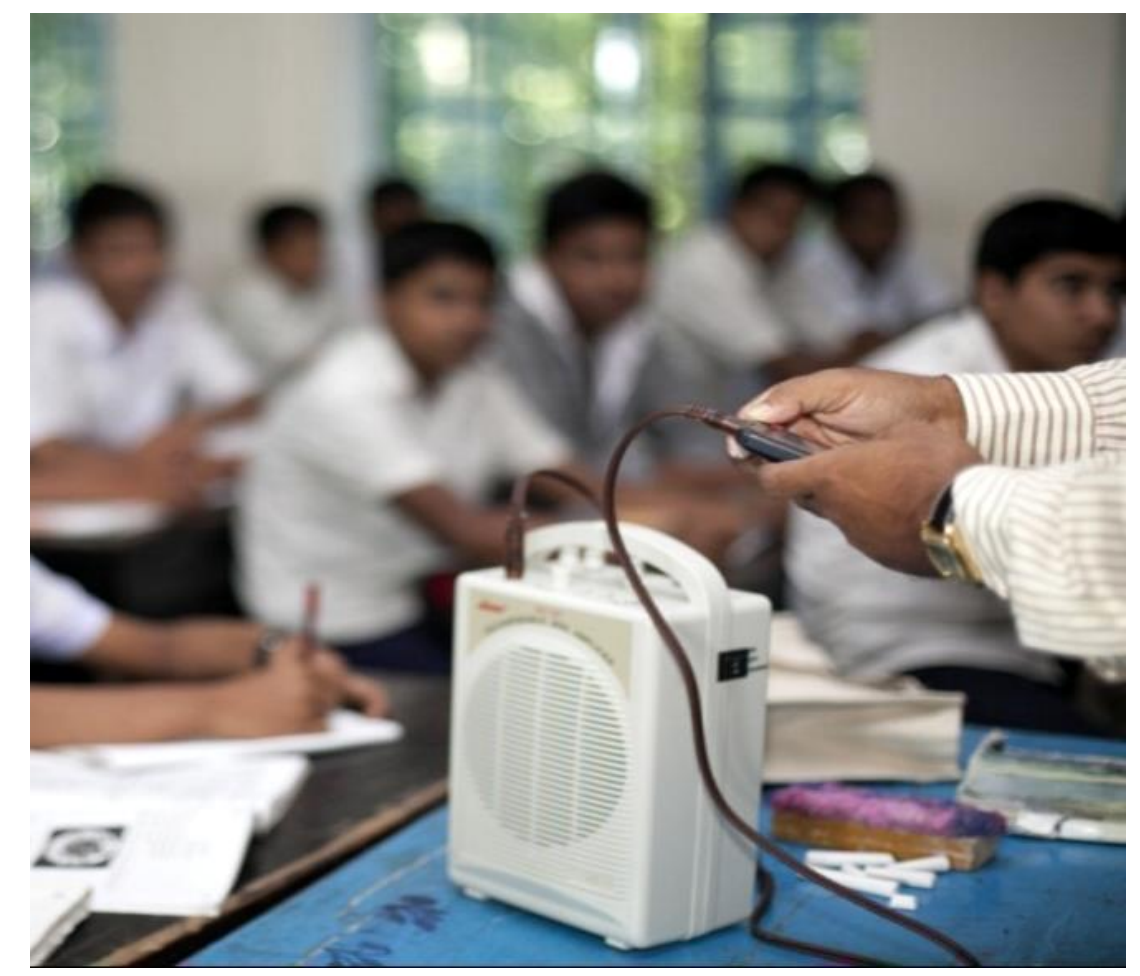

Figure 7 EIA's mobile-phone-based technology kit known as 'the trainer in your pocket'

\section{EIA's 'trainer in your pocket'}

Following the success of the pilot studies, all of EIA's TPD materials were revised for use with the new mobile-phone-based 'trainer in your pocket'. We illustrate how the 'trainer in your pocket' is used in two examples of ODL. The first explicitly illustrates how teachers are presented with TPD resources, in the form of mediated authentic videos (MAVs). The second outlines EIA's bespoke English for Specific Purposes (ESP) programme, English Learning for Teachers (EL4T), which aims to increase teachers' communicative English language proficiency and teaching practices by providing ESP instruction directly related to the national textbook.

\section{Teacher TPD delivered through ODL on low-cost mobile phones}

Each primary and secondary teacher received the new technology kit and an EIA produced Teacher Guide. The teachers' TPD materials are centred on the MAVs and supported by the print Teachers' Guide. The TPD materials are divided into eight modules and each emphasizes the four skills of listening, speaking, reading and writing. 
The MAVs are authentic classroom-based TPD films, illustrating examples of student-centred English teaching lessons that emphasize a communicative approach using the government textbook.

Each of the MAVs starts with a female narrator, who is the 'expert' voice, introducing each TPD focus of the module. What makes EIA's MAV resources for TPD innovative is that the narrator first sets a 'viewing task' prior to the teachers watching the video and then poses reflective questions for them to consider and respond to after practising similar techniques in their own classrooms. The expert voice of the narrator enables EIA to move away from the default cascade model of large-scale professional development where information is passed down from the original author, through a range of master trainers, eventually reaching the teacher in an often 'diluted' form (Robbins \& Latchem, 2003).

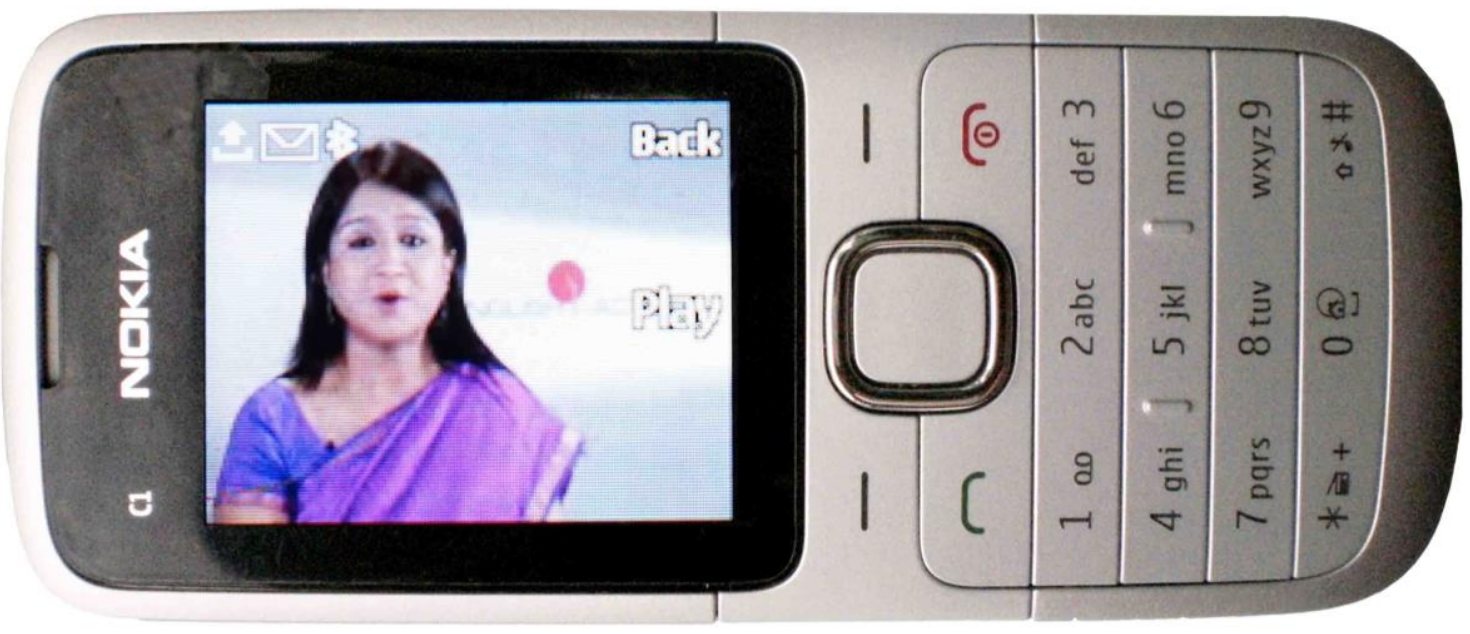

Figure 8 EIA's narrator presenting the TPD through a MAV

To understand how the 'trainer in your pocket' works for teacher TPD, we provide an example from the EIA produced Secondary Teacher Guide: Secondary Teaching and Learning from Module 8 entitled 'Looking back and moving forwards'. For Module 8, there are three video clips, four audio files and a 'Teachers Talking' audio file for extended reflection on practice. In the first film, the narrator introduces the module, as follows:

Hello and welcome to Module 8 - Looking back and moving forwards. This is the final module of the English in Action programme. We begin with Part 1 (SM8-V1) the communicative classroom. As you have read in the module 8 introduction, you are going to watch video clips of a lesson for Class 7, Unit 4, Lesson 10.

In the first clip, you are going to watch the first part of the lesson. As you watch the 
video clip, think about these questions:

- What is the focus of the first part of the lesson?

- What do the students practise?

Now watch the clip and take notes.

This is followed by a film of the classroom with the students reviewing vocabulary from an earlier lesson and the teacher introducing new vocabulary that they will encounter (Figures 5 and 6) in their texts. The teacher then writes three questions on the board and asks the students to read a story and look for the answers to these questions. Afterwards, students switch papers and correct their partner's answers. There are over 60 female students in the classroom.

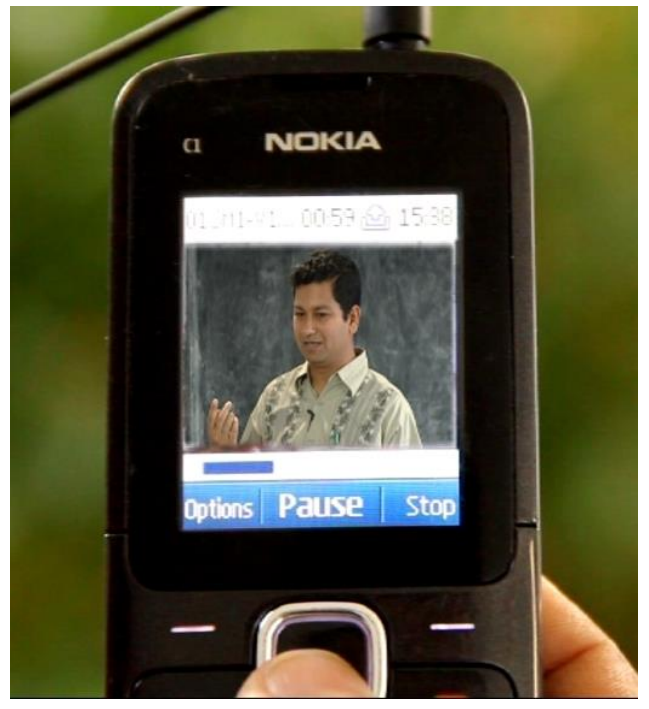

Figure 9 Communicative English teaching

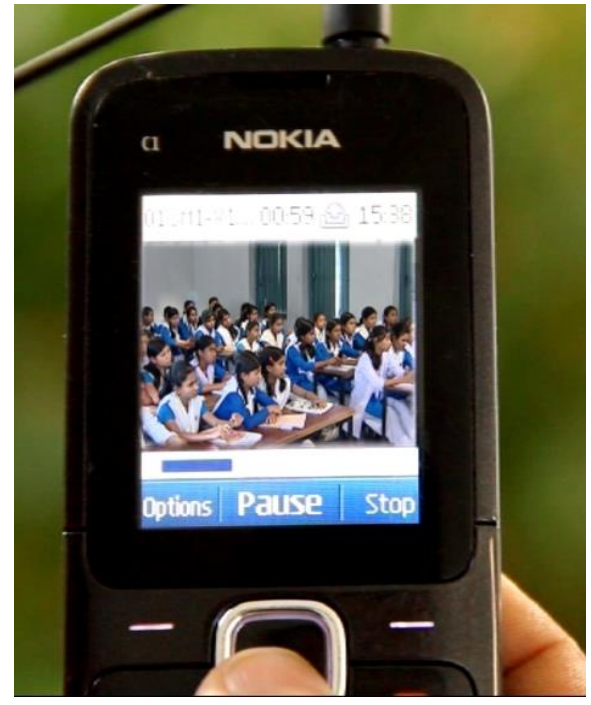

Figure 10 Students engaging in communicative English

Afterwards, the narrator comes back on and says:

The first part of the lesson involves a short reading passage - the first part of a story. The students read the story, but before they do, the teacher prepares them for the story by reminding them of the previous lesson, and then introducing them to some words from the story. This is a pre-reading activity. As the students practise these words, they are already thinking about the story and what will happen, and this helps them to understand the story when they read it.

The students then answer the questions on the board. Do you remember what the 
teacher said, back in Module 2, when asking students to read a passage and answer questions based on it? - 'Remember, you don't have to read every word.' The students here are NOT reading every word, they are scanning the text in order to find the information to answer the three questions. The teacher then asks them to switch papers with their partner - why does he do that? Well, think back to Module 5. It helps students to become more independent and to think about their learning and keeps them engaged in the class and in their learning. Did you also notice how the teacher asks students from around the class and always praises the students?

Let's continue watching - why does the teacher ask the students to write their own question about the story?

The video then continues with students writing their own questions and asking their partners to answer them before the teacher invites selected students to ask their questions to the whole class.

The video narrator then comes back on and summarizes what the teachers have viewed, and focuses on the idea of 'recycling language' and the communicative English language learning activities the students engaged in:

After reading the story, the students each write a question about it. Here they are recycling language, and they are also checking that they understood the key points of the story. They ask each other questions in pairs, and as a whole class. This also helps the teacher to see if the students have understood the passage.

So now for the second question - what do the students practise?

\section{[PAUSE]}

The students practise reading of course, but they also practise listening - they listen to the teacher who is speaking in English, and they listen to the other students. They also practise a little speaking and writing - they each write a question about the story, and they answer each other's questions.

Although this lesson focuses on reading, the teacher uses English as much as possible with his students, and tries to make the lesson as communicative as possible.

Now go to Module 8 'Try in the Classroom 1' in the Teacher Guide where there is a task for you to try so that you can make your own classroom more communicative. 


\section{English Language for Teachers (EL4T)}

English language teachers in government and non-government schools in Bangladesh are non-native speakers of English. As a result, their communicative English language proficiency is low. Thus, many English teachers use the grammar translation method of teaching. This method does not focus on teaching students how to communicate in English (Prator \& Celce-Murcia, 1979); rather teachers 'translate' the text using Bangla, focusing on meaning rather than communication. In order to address this challenge, EIA developed an innovative ODL course called English Language for Teachers (ELAT) for both primary and secondary English language teachers (Shrestha, 2012).

EL4T is an ODL self-study English for Specific Purposes (ESP) course, with audio files accessible through micro SD cards on teachers' mobile phones that are used alongside a print guide. ELAT was designed to provide teachers with access to the ESP demands of Bangladesh's national textbook series, English for Today. It does this by explicitly focusing on speaking and listening skills that take into account functional English language, structures and vocabulary of direct relevance to communicative classroom teaching. ELAT contains two sets of bilingual (Bangla and English) audio- and print-based materials for them to use at their own pace. There is a total of 60 hours of ODL activities for both primary and secondary teachers.

\section{Fostering a 'quiet revolution' in the provision of teacher professional development}

The previous examples illustrate how EIA is using the 'trainer in your pocket' for large-scale TPD within a SBPD model and for self-study within an ODL platform. Paramount to EIA's TPD is that teachers can revisit the videos to view successful student-centred teaching practices in classrooms similar to their own. Afterwards, they can compare and reflect upon EIA's TPD resources alongside their uptake of student-centred communicative English language teaching practices. We collaboratively problematized the 'probable' future on offer because we deeply care about the future of all children, particularly children in Bangladesh. Drawing on our 'little "c" creativity', we thought differently about how to leverage the power of mobile phones to co-create more sustainable educative futures for the Bangladeshis teachers and students we work with.

We argue that the use of the 'trainer in your pocket' within the SBPD model — the result of collaborative futures thinking - is working to foster a 'quiet revolution' (Chappell et al. 2011, p. 150) in the provision of TPD at scale in Bangladesh. This is because researchers within EIA engaged in possibility thinking to co-construct possible futures to challenge current assumptions about the technological and pedagogical future of Bangladesh. We did this to provoke other pathways than what was to likely happen in the 'probable' future.

We believe our approach is 'changing learning and changing lives' because, over time, 
we have witnessed noticeable changes in the creative community of teachers and students we have been lucky enough to work with. For example, Bangladeshi teachers are using their own 'little " $c$ " creativity' to maximize the learning potential of the 'trainer in your pocket'. As the project scales up in its final phase, we are certain all stakeholders can engage in the collaborative, collective and co-creative endeavour needed - that assumes commitment to excellence and engaged involvement (Chappell, Walsh \& Craft, 2013) - to institutionalize all of EIA's TPD resources, making them open educational resources (OERs). Thus, with the rapid changes in technology, teachers across Bangladesh will have access to the pedagogical resources they need to challenge the status quo as they themselves engage in possibility thinking to transition from what is to what might be through 'what if?' and 'as if' thinking. (Craft, 2012, p. 182). '

\section{References}

Access to Information, Prime Minister's Office. (2009). Digital Bangladesh Concept Note. Available at: http://114.130.56.63/digital-bangladesh

Bell, W. (1997). Foundations of futures studies. New Brunswick, NJ, Transaction Publishers.

Cascio, J. (2009). Futures thinking: The basics. Available at http://www.fastcompany.com/blog/jamais-cascio/open-future/futures-thinking-basics. Accessed on 01 July 2010.

Chappell, K., L. Rolfe, A. Craft, \& Jobbins, V. (2011). Close encounters: Dance partners for creativity. Stoke-on-Trent: Trentham Books.

Craft, A. (2001). Little c creativity. In A. Craft, B. Jeffrey, \& M. Leibling (Eds.), Creativity in education, London: Continuum, 45-61.

Craft, A. (2012). Childhood in a digital age: Creative challenges for educational futures. London Review of Education, 10(2), 173-190.

Craft, A., Chappell, K., \& Walsh, C.S. (2013). Deliverable 2.1.1 C2Learn learning design for creative emotional reasoning (CER). C2Learn: Creative emotional computational tools fostering co-creativity in learning processes. Accessed from:

http://www.c2learn.eu/sites/default/files/C2Learn_D2_2_2_Learning_Design_for_CER.p df

Ekanayake, S. Y., \& Wishart, J. (2014). Integrating mobile phones into teaching and learning: A case study of teacher training through professional development workshops. British Journal of Educational Technology, 46 (1), 173-189.

Md. Monodol, S. \& Walsh, C. (2011). Leveraging mobile phones to make 'Vision 2021' a reality. Proceedings from eAsia 2011 Realizing Digital Nation Conference, Dhaka Bangladesh December 1-3. 
WALSH, WOODWARD, SOLLY AND SHRESTHA

National Curriculum \& Textbook Board (2003). English for today. Dhaka, Bangladesh: National Curriculum and Textbook Board, Ministry of Education.

Onguko, B. (2014). JiFUNzeni: A blended learning approach for sustainable teachers' professional development. Electronic Journal of E-Learning, 12(1), 77-88.

Power, T., Shaheen, R., Solly, M., Woodward, C., \& Burton, S. (2012). English in action: School based teacher development in Bangladesh. Curriculum Journal, 23(4), 503-529.

Prator, C.H., \& Celce-Murcia, M. (1979). An outline of language teaching approaches. In M. Celce-Murcia, \& L. McIntosh (Eds.), Teaching English as a second or foreign language. New York: Newbury House.

Robbins, B., \& Latchem, C. (2003). Open and distance teacher education: Use and models. In B. Robinson \& C Latchem (Eds.), Teacher education through open and distance learning (Vol. 3). London: Routledge/Falmer.

Sardar, S. (1999). Rescuing all our futures. WestportCT, Greenwood Press.

Schuck, S., Aubusson, P., Kearney, M., \& Burden, K. (2013). Mobilising teacher education: A study of a professional learning community. Teacher Development, 17(1), 1-18.

Shrestha, P. (2012). Teacher professional development using mobile technologies in a large-scale project: Lessons learned from Bangladesh. International Journal of Computer-Assisted Language Learning and Teaching, 2, 34-49.

Shrestha, P. (2013). English language for teachers (EL4T): A course for EFL teachers. In: TESOL 2013 International Convention: Harmonising ESP practice in EFL contexts through curricular innovation, 20-23 March 2013, Dallas, Texas.

Walsh, C. S. (2011). E-learning in Bangladesh: The 'trainer in your pocket'. In IADIS International Conference on e-Learning 2011, a part of the IADIS Multi Conference on Computer Science and Information Systems 2011, 20-23 July 2011, Rome, Italy.

Walsh, C., \& Power, T. (2011). Rethinking development and the use of mobile technologies: Lessons from Bangladesh. In Global Learn Asia Pacific 2011, 28 April-01 May, 2011.

Walsh, C. S., Power, T., Khatoon, M., Biswas, S. K., Paul, A. K., Sarkar, B. C., \& Griffiths, M. (2013). The 'trainer in your pocket': Mobile phones within a teacher continuing professional development program in Bangladesh. Professional Development in Education, 39(2), 186-200.

Woodward, C., Griffiths, M., \& Solly, M. (2014). English in action: A new approach to TPD through the use of mediated video, peer support and low cost mobile phones. In D. Hayes (Ed.), Innovations in the continuing professional development (TPD) of English language teachers, British Council. 